\title{
APPLICATION OF SLUDGE, ORGANIC SOLID WASTES AND YARD TRIMMINGS IN AEROBIC COMPOST PILES
}

\author{
P. CHAZIRAKIS ${ }^{1}$ \\ A. GIANNIS ${ }^{1,2^{*}}$ \\ E. GIDARAKOS ${ }^{1}$ \\ J-Y. WANG ${ }^{2}$ \\ R. STEGMANN ${ }^{2}$
}

Received: 07/03/11

Accepted: 09/11/11

\author{
${ }^{1}$ Dept. Environmental Engineering, Technical University of Crete \\ Politechnioupolis, 73100 Chania, Greece \\ ${ }^{2}$ Residues and Resource Reclamation Centre (R3C) \\ Nanyang Technological University \\ Singapore 639798, Singapore
}

*to whom all correspondence should be addressed: e-mail: apostolos.giannis@enveng.tuc.gr

\begin{abstract}
The effects of different mixture ratios of sewage sludge (SS), organic fraction of municipal solid waste (OFMSW) and yard trimmings (YT) on the performance of composting process were investigated in this study. The high water content and the proper carbon/nitrogen ratio make sludge ideal for this procedure, improving the characteristics of the initial composting mixture. OFMSW and YT enable the production of a quality product that may be used as a soil conditioner. Therefore, piles of about $1 \mathrm{~m}^{3}$ were prepared by mixing OFMSW, SS and YT in four different ratios (w/w) [only OFMSW, OFMSW:SS = 2:1, OFMSW:SS:YT = 3:1:2, and OFMSW:SS:YT = 4:1:2]. The piles were kept in controlled aerobic conditions for 10 weeks. The temperature of the piles was measured daily (for the first 4 weeks) and ranged between $60-70{ }^{\circ} \mathrm{C}$, while air was provided to the piles by mechanical turning. Results showed that the pile OFMSW:SS:GW $=3: 1: 2$ was most beneficial in composting, since its ability to accumulate and retain heat and achieve high organic matter degradation. The final compost products contained $\mathrm{C} / \mathrm{N}$ ratio less than 15 indicating that achieved mature and stable products. The heavy metal contents in the final composts were several times lower than regulation limits.
\end{abstract}

KEYWORDS: co-composting, organic solid waste, sewage sludge, yard trimmings, phytotoxicity.

\section{INTRODUCTION}

Due to the rapid increase of global population, municipal solid waste (MSW) as well as sewage sludge (SS) production has dramatically increased the last 20 years. Environmental pollution caused by MSW and SS has become a serious social problem which hinders urban development (Lu et al., 2009). Many landfills have closed because they are full. It is critical to find new ways for effective management of such wastes and reduce their impact on the environment (Gazi et al., 2007). The municipal organic wastes constitute an alternative source of organic matter for soils (Banegas el al., 2007). However, their use without prior stabilization represents a high risk because of the potentially negative effects of any phytotoxic or pathogenic substances they may contain and because of their very unstable nature (Garcia et al., 1993).

Composting is regarded as a suitable way of recycling such wastes since it helps to solve the problem of their disposal. Most of the engineering research on composting treatment aims to identify how the waste characteristics and the composting conditions influence both the compost quality and the environmental impacts of composting (de Guardia et al., 2010). At the same time, composting yields a valuable product that can be used by farmers, landscapers, horticulturists and property owners as a soil amendment to enhance the texture and appearance of soil, increase soil fertility, improve soil structure and aeration, increase the ability of the soil to retain water and nutrients and moderate soil temperature, reduce erosion, and suppress weed growth and plant disease. Ultimately, as a type of recycling, composting in many ways represents a more efficient and safer 
use of resources than landfilling or incineration. During the composting process, substrate is placed in a pile or windrow where decomposition takes place. The rate of decomposition depends on the level of technology used as well as on physical, chemical, and biological factors as microorganisms, oxygen levels, moisture content, and temperature. Composting works better when these factors are carefully monitored and controlled.

The high moisture content of sludges means that they cannot be composted alone and they need to be mixed with dry materials (such as sawdust, yard trimmings or solid waste). MSW usually has the characteristics of an incompact structure and a relatively high carbon to nitrogen ratio $(\mathrm{C} / \mathrm{N})$, whereas SS usually has the characteristics of a dense structure due to its high moisture content and low $\mathrm{C} / \mathrm{N}$. Therefore, SS requires a larger amount of bulking agent to absorb moisture, provide the composting mass with an appropriate degree of sponginess and aeration, and increase the C/N (Tremier et al., 2005; Banegas et al., 2007; de Guardia et al., 2008). Thus, mixing MSW and SS can thus improve the structure and $\mathrm{C} / \mathrm{N}$ of sewage sludge, increase the nitrogen content of MSW for the compost product, and meet the goal of fast sanitization and stabilization. Composting is a popular way to treat organic solid waste, but there are many factors that affect the composting process, such as the proportions of the mixture, the aeration rate, oxygen consumption rates, compost recycling, moisture content, temperature, $\mathrm{pH}$, nutrient content and $\mathrm{C} / \mathrm{N}$ since they determine the optimal conditions for microbial development and organic matter degradation (Meunchang et al., 2005; Bernal et al., 2009). Despite many studies exist on the treatment of SS, YT and MSW, there are only a few available on co-composting. The ratios of SS, YT and MSW found in the literature in composting studies are diverse. Nowadays, composting facilities have developed a ratio of wastes that they like.

The purpose of this research was to fill the gap in the existing field of mixing ratios to improve the composting process performance. Therefore, it was evaluated the effects of co-composting of SS and GW mixed with the OFMSW in different ratios. During the process, it was evaluated the temperature, $\mathrm{pH}$, organic carbon and nitrogen content. In addition, to assess the compost quality the Germination Index ( $\mathrm{Gl}$ ) and heavy metals concentration were measured at the final compost products. This study can be used as a guide for full scale applications.

\section{MATERIALS AND METHODS}

Three types of materials were used in this experiment: Organic Fraction of Municipal Solid Waste (OFMSW), Yard Trimmings (YT) and dewatered Sewage Sludge (SS). The OFMSW was obtained from the MBT plant of Korakia (Chania, Crete). The physical composition of OFMSW (by weight) was as follows: organic $60.4 \%$, paper $26.6 \%$, metal $3.4 \%$, glass $3.2 \%$, plastic $6.4 \%$. The YT were collected from outdoor piles of stored grounded material. The samples were segregated by hand to remove any non-compostable materials. OFMSW and YT were shredded in order to mix them for the biological processes. The SS was collected from the wastewater treatment plant of Chania, which treats mainly domestic wastewater. The physicochemical characteristics of the wastes are presented in Table 1.

Table 1. Physicochemical characteristics of the raw materials

\begin{tabular}{llccc}
\hline \multicolumn{2}{c}{ Parameter } & OFMSW & Wood Branches & $\begin{array}{c}\text { Sewage } \\
\text { Sludge }\end{array}$ \\
\hline moisture & $\%$ & 54.1 & 46.7 & 82.9 \\
total solids & $\%$ & 45.9 & 53.3 & 17.1 \\
organic matter & $\%$ & 61.1 & 82.70 & 79.9 \\
& $\% \mathrm{C}$ & 35.2 & 45.9 & 41.8 \\
\multirow{4}{*}{ chemical composition } & $\% \mathrm{H}$ & 3.8 & 6.0 & 5.5 \\
& $\% \mathrm{~N}$ & 2.0 & 1.2 & 7.6 \\
& $\% \mathrm{~S}$ & 0.7 & 0.5 & 1.7 \\
ash & $\% \mathrm{O}$ & $19 . \%$ & 40.7 & 23.3 \\
C/N & $\%$ & 38.9 & 5.7 & 20.1 \\
\hline
\end{tabular}


Homogenization of the mixture is critical for aeration, but the structure of SS is viscous and not easy to spread. The ratio of the SS, OFMSW and YT was chosen to achieve optimal homogenization and incompact structure. Therefore, eight piles were produced by mixing OFMSW, SS and YT in four different ratios [two piles OFMSW (A), two piles (w/w) OFMSW:SS=2:1 (B), two piles OFMSW:SS:YT=3:1:2 (C), and two piles OFMSW:SS:YT=4:1:2 (D)]. Each pile had a volume about 1 $\mathrm{m}^{2}$. The volume of the piles was sufficient to ensure a thermophilic composting process. During the composting process, the piles were turned periodically (every 3-4 days) for 4 months to maintain adequate $\mathrm{O}_{2}$ levels and temperature. The moisture content of the piles was maintained at $50-60 \%$ of their water holding capacity throughout the composting period and the temperatures of the interior of each pile were monitored daily at different points for the first two weeks, every 3-4 days after that period with a digital temperature probe (Gresinger). The moisture content of the pile was determent weekly and when it was necessary the piles were watered by addition of water. Samples were taken randomly from within the piles and from the outer layer every three days for the first two week and weekly afterwards. The samples were dried, homogenized and sieved through a $0.5 \mathrm{~mm}$ sieve and then stored for chemical analysis. Data shown in the tables and figures are the mean of average values of the two composting piles of each treatment.

The samples were milled prior the analyses. For moisture content determination, a given sample was weighed into a crucible and put into an oven heated at $70{ }^{\circ} \mathrm{C}$ overnight and reweighted. The percent organic matter content in the composting piles was determined by gravimetric loss-onignition of oven-dried samples, burning to ashes in a muffle furnace at $600{ }^{\circ} \mathrm{C}$ for $24 \mathrm{~h}$. Moisture and organic matter contents were analysed according to Standard Methods (APHA, 2005). The pH was determined in aqueous extract (substrate:extractant $=1: 5)$ using a $\mathrm{pH}$ electrode (Crison $\mathrm{pH} 25)$. The elemental composition (CHNS-O) of the OFMSW, SS and YT were determined by flash combustion at $1020{ }^{\circ} \mathrm{C}$ using a EuroVector EA3000 series elemental analyzer. For the heavy metals analysis, the extraction of aqua regia soluble elements method was used in dried samples and the extractants were analyzed by AAnalyst 700 Perkin Elmer graphite furnace atomic absorption analyzer. The germination experiment was carried out on using the PHYTOTOXKIT closed test from MicroBioTest Inc. Compost samples as well as a control soil were added to the provided PVC dishes. Seeds of Lepidium Sativum were placed above a filter paper over the wet compost and soil. The germination percentages with respect to the control and root lengths were determined after 3 days. The seed germination bioassay was evaluated according to Tam \& Tiquia (1994) and Komilis et al. (2005).

\section{RESULTS AND DISCUSSION}

\subsection{Compost materials temperatures and pHs}

The curves in Fig. 1 show the temperature variations of the composting piles as a function of the waste mixtures and composting time. The temperature follows a typical temperature profile for composting (mesophilic-thermophilic-mesophilic). As seen, in each pile the temperature increased from the ambient temperature to more than $60{ }^{\circ} \mathrm{C}$ within 3 days, and showed rapid initiation of the compost process. The temperature remained constant for 9 days and then started decreased gradually. Finally, the temperature of each pile approached the ambient temperature at day 65 . During the composting process, the water removal was mainly due to evaporation of water as a consequence of microbial heat generation increasing the free space for aeration. Comparing the piles, it seems that higher temperature was achieved in the mixtures with yard trimmings ( $C$ and $D$ pile). The addition of trimmings facilitated air distribution resulting better microbial activity. These results confirm the assumption that the self-heating ability is closely correlated to the waste characteristics (de Guardia et al., 2010). As the organic compounds were degraded, the piles become richer in more stable compounds which were less accessible to the microorganisms and so their activity, and corresponding temperature decreased to ambient temperature.

Regarding the $\mathrm{pH}$ profiles, a slight increase was observed during composting process (Fig. 2). In the first weeks of composting the intense microbial activity and organic matter degradation led to the formation of ammonium and therefore an increase in $\mathrm{pH}$. Lowering the high $\mathrm{pH}$ lowers ammonia volatilization and reduces odors, favoring a balanced microbial population (Moldes et al., 2007). At the end of composting, values between 7.5 and 8.2 were observed in all the piles similar to the $\mathrm{pH}$ range reported by Bernal et al. (1998) for composts derived from various organic waste sources like sewage sludge, animal manure, city refuse, industrial and plant residues. 


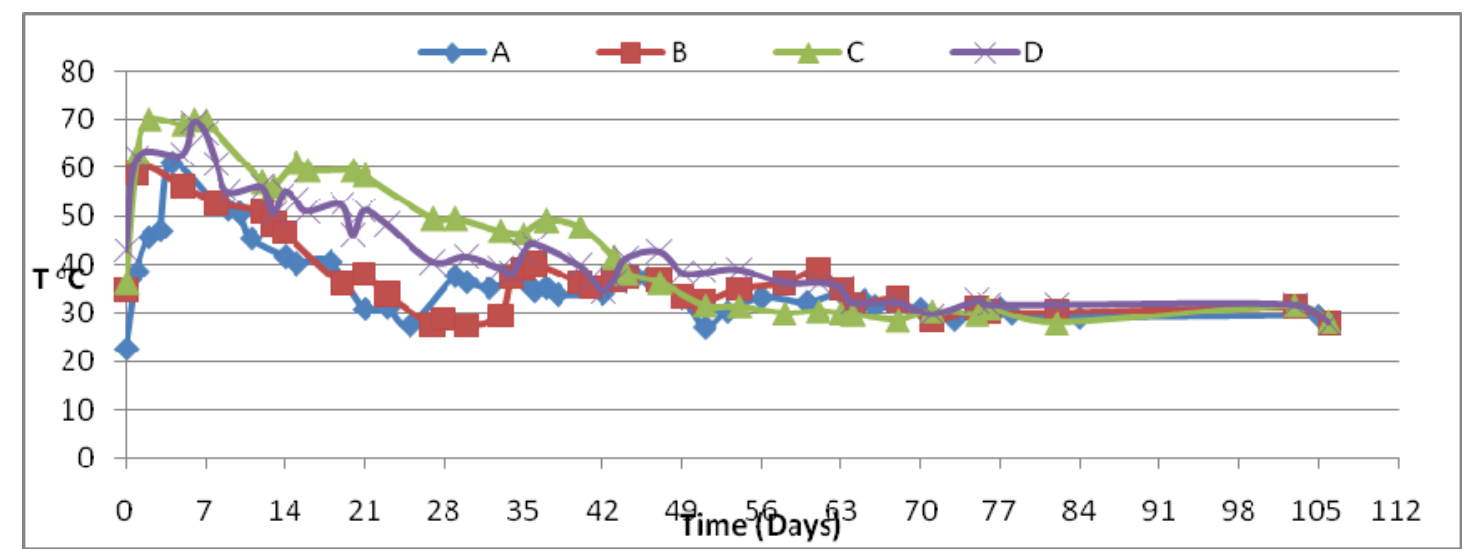

Figure 1. Temperature variations of composting piles

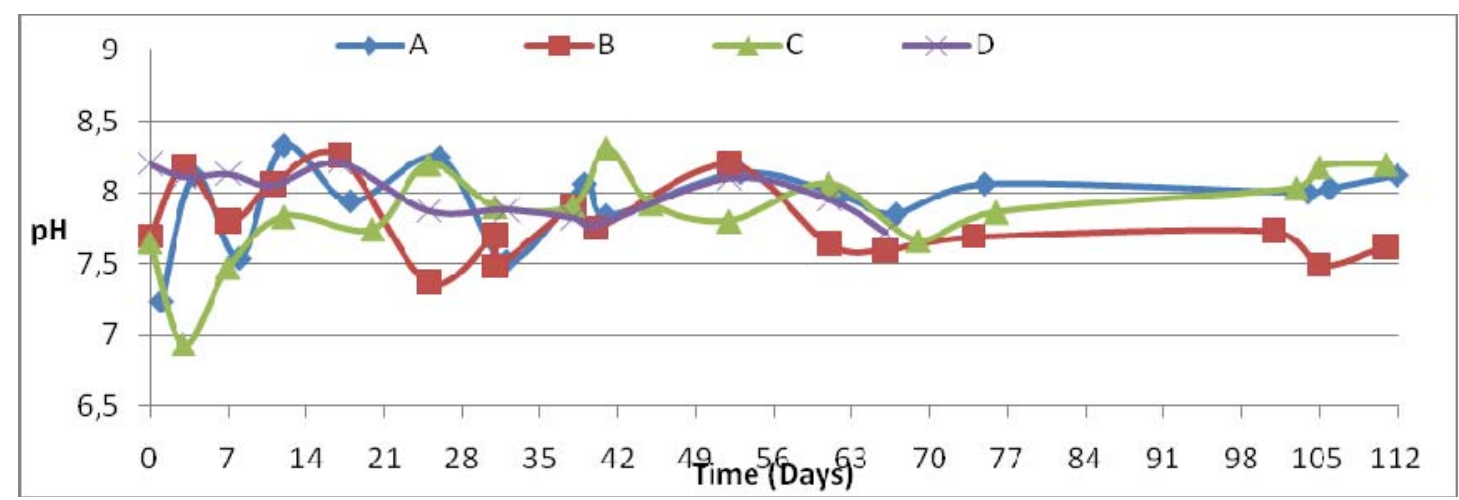

Figure 2. $\mathrm{pH}$ profiles of composting piles

\subsection{Chemical characteristics of composting process}

Organic matter is reported in terms of total OM (determined by weight loss after combustion). There is no absolute level of organic matter that is ideal in terms of compost quality, but rather the quantities must be viewed in relation to the age of the compost, its nitrogen content, and its intended use. It is useful for purposes of composting to report the initial and the final $\mathrm{OM}$, as this gives an idea of the extent of decomposition (Jimenez and Garcia, 1991).

The quantity and form of nitrogen present in compost is important in shaping the quality of the material. The ratio of $\mathrm{C} / \mathrm{N}$ is often used to assess the rate of decomposition of compost mixtures, as it may reflect the maturity of the compost. However, caution is necessary before taking any action based only on the $\mathrm{C} / \mathrm{N}$ ratio. It must be considered that not all the carbon is available for microbial use. Moreover, if nitrogen is lost, $\mathrm{C} / \mathrm{N}$ ratios may increase during late stages of composting. Therefore, $\mathrm{C} / \mathrm{N}$ values must be weighed against observed decomposition traits. Compost may be considered mature when the $\mathrm{C} / \mathrm{N}$ ratio is approximately 17 or less, unless lignocellulose material remains (Wong et al., 2001).

The changes in the main chemical parameters (carbon, nitrogen) during the composting are shown in Fig. 3. The content of $C$ was decreased by translating into carbon dioxide and water in all piles after composting. These changes occurred in all treatments at the end of composting process because the molecules degraded by intense microbiological activity during composting became reorganized to form more condensed compounds rich in aromatic components (Wei et al., 2007). A decrease in nitrogen was expected due to mineralization of nitrogen and transformation to ammonia and later nitrate. However, this trend cannot be observed, because only a little portion of organic nitrogen is actually transformed (Sanchez-Monedero et al., 2001). Additionally, the C/N ratios decreased (Fig. 4). The C/N ratio corresponding to all compost piles evaluated in the present study was satisfactory (less than 15). Furthermore, soluble nitrogen maybe present in the compost 
material as ammonia, but this is not desirable since it is more volatile and can be lost if the material is surface spread.
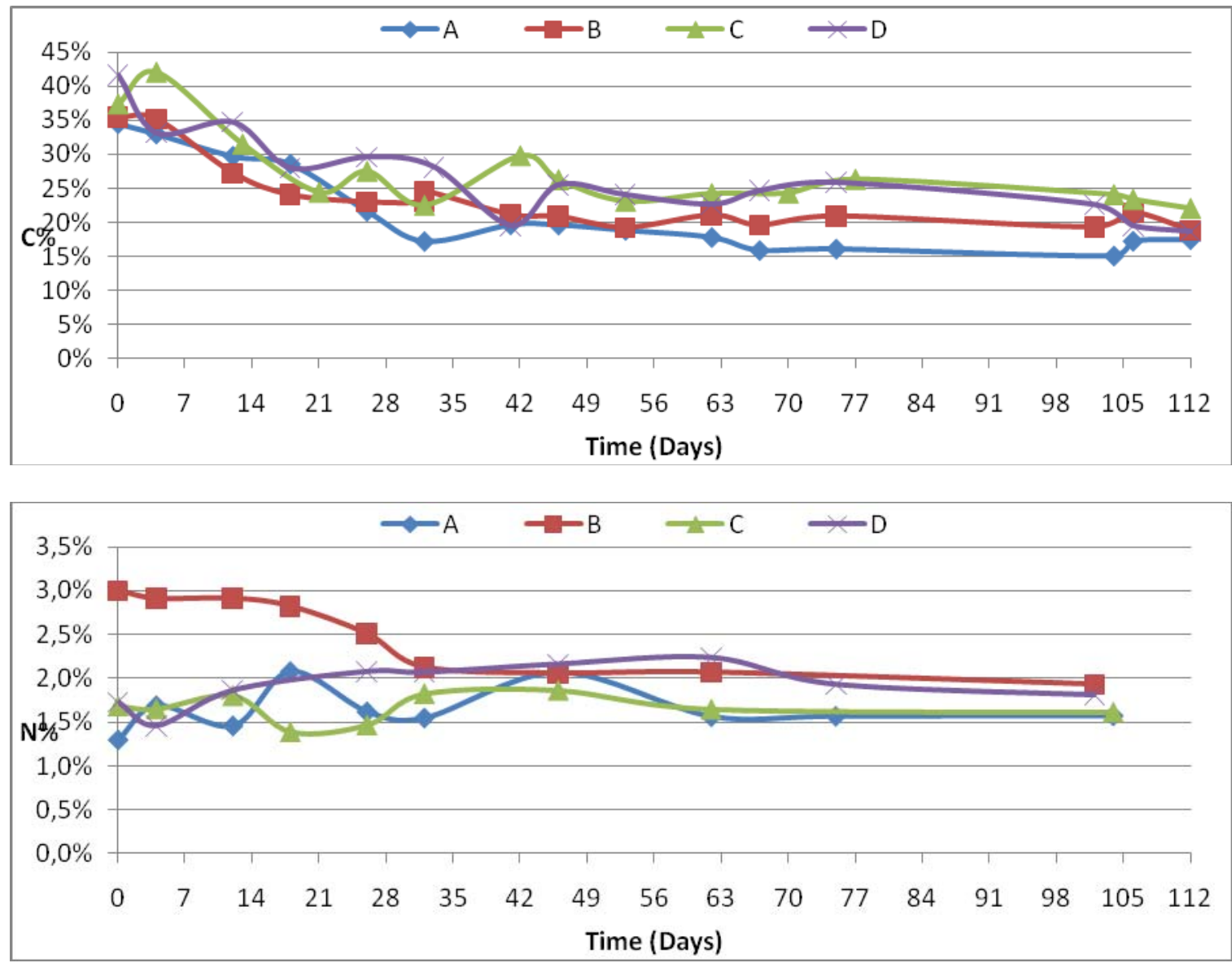

Figure 3. Total carbon and nitrogen mass balances

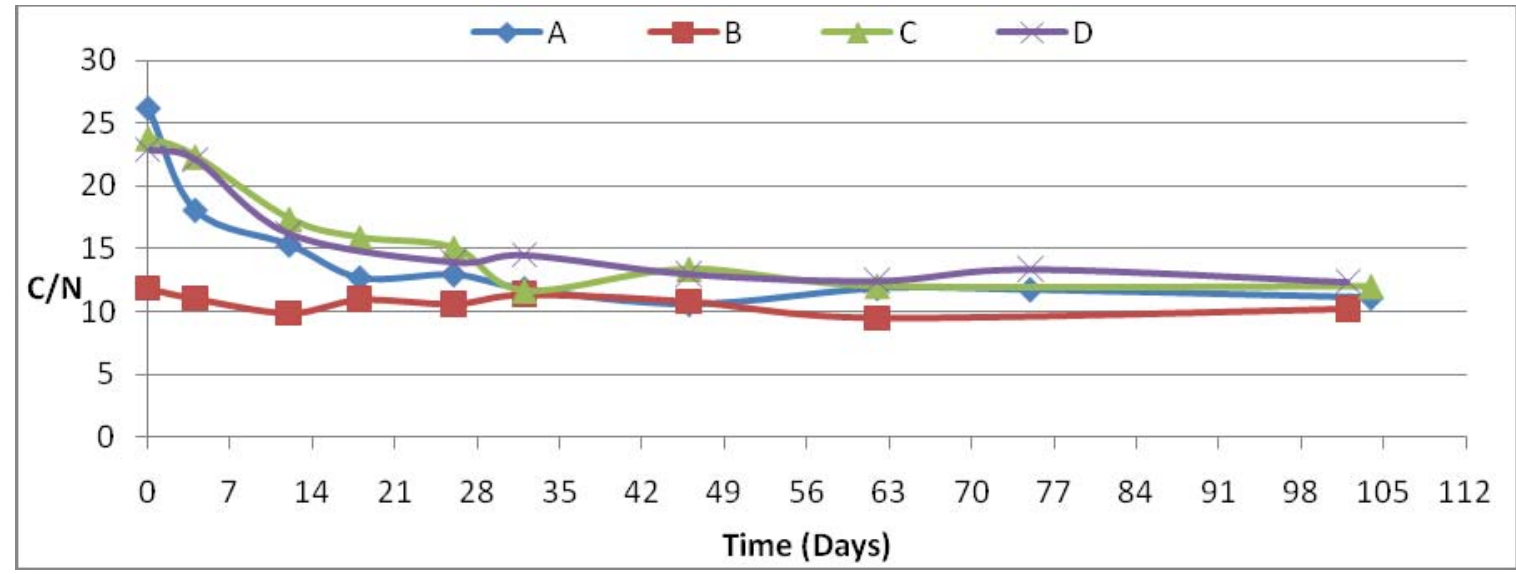

Figure 4. Total carbon/nitrogen ratio

\subsection{Compost maturity}

One of the problems posed by direct use of sewage sludge in agriculture is the risk of plant and human contamination by pathogens and heavy metals. According to Stentiford (1996), temperatures more than $55{ }^{\circ} \mathrm{C}$ favor sanitation, values between 45 and $55{ }^{\circ} \mathrm{C}$ favor degradation, and 35 and $40{ }^{\circ} \mathrm{C}$ favor microbial diversity. The maximum temperatures during composting process were ranged between 60 and $70{ }^{\circ} \mathrm{C}$. These temperatures, which were maintained for days during the process, ensured that the composting process followed was suitable for stabilizing organic matter and suppressing pathogenic microorganisms. 
The mean values of heavy metals concentrations of raw materials and the final compost products in the duplicate compost piles are shown in Table 2. The heavy metal contents $(\mathrm{Zn}, \mathrm{Cu}, \mathrm{Ni}, \mathrm{Cr}, \mathrm{Cd})$ in the final composts were several times lower than regulation limits prescribed by Directive 2007/64/EC for fertilizers, including compost. According to Amir et al. (2005) the mobility and bioavailability of heavy metals are dependent on other physico-chemical properties of the medium besides total metal contents, such as decomposition of organic matter, humic substance content, $\mathrm{pH}$ and the affinity of metals for various chemical forms. This study indicated that the metals were in stable forms (residual fraction) and consequently considered unavailable for plant uptake. The amount of potentially bioavailable metals was less than $2 \%$.

Table 2. Heavy Metals concentration in raw materials and the final compost products

\begin{tabular}{cccccc}
\hline & $\mathrm{Zn}$ & $\mathrm{Cu}$ & $\mathrm{Ni}$ & $\mathrm{Cr}$ & $\mathrm{Cd}$ \\
\hline $\mathrm{A}$ & 140,38 & 26,56 & 37,63 & 15,47 & 0,20 \\
B & 317,06 & 35,54 & 40,41 & 13,77 & 0,46 \\
C & 283,03 & 43,66 & 21,92 & 20,71 & 0,25 \\
D & 241,51 & 8,64 & 20,50 & 47,67 & 0,44 \\
OFMSW & 140,39 & 16,90 & 37,63 & 15,47 & 0,28 \\
GW & 362,31 & 26,79 & 3,44 & 14,85 & 0,64 \\
DS & 725,35 & 258,96 & 21,38 & 54,04 & 4,47 \\
Limit values & 300 & 100 & 50 & 100 & 1 \\
\hline
\end{tabular}

*values in $\left(\mathrm{mg} \mathrm{kg}^{-1}\right)$ of dried sample

In order to employ the evaluated composts as plant growing media, the Germination Index (GI) in closed tests was measured (Table 3). Results showed that the seeds Lepidium Sativum weren't germinated in piles $A$ and $B$ due to the phytotoxic effect of some plant growth inhibiting substances such as ammonia (data not shown). This is an indication that the compost was probably immature (Zucconi et al., 1981). For the piles C and D, the seed germination was very high, but the root elongation in pile $D$ was relatively lower. Therefore, only pile $C$ has satisfied the recommended limit for use in crop production. For application and use of compost in open space gardening, the Association of Swiss compost plants (VKS) recommended for the closed test a limit of $25 \%$ plant growth (Cofie et al., 2009).

Table 3. Germination index of co-composting products (\%)

\begin{tabular}{cccc}
\hline & $\begin{array}{c}\text { Relative seed } \\
\text { germination (\%) }\end{array}$ & $\begin{array}{c}\text { Relative root } \\
\text { elongation (\%) }\end{array}$ & $\mathrm{Gl}$ \\
\hline A & 0 & 0 & 0 \\
B & 0 & 0 & 0 \\
C & 75.03 & 61.90 & 46.44 \\
D & 63.47 & 29.47 & 18.70 \\
\hline
\end{tabular}

\section{CONCLUSIONS}

This work aimed to study the characteristics of the co-composting of SS, OFMSW and YT. The present study showed that the addition of YT enhances the composting process due to its ability to accumulate and retain heat and achieve high organic matter degradation. The final compost products were well sanitized as a result of the high temperatures achieved. The changes in the temperature and chemical parameters of different pile ratios indicate that the OFMSW:SS:GW = 3:1:2 is the best for accumulating heat and maintaining high temperature, and could achieve the highest organic matter degradation in the final compost product.

\section{REFERENCES}

Amir S., Hafidi M., Merlina G. and Revel J.C. (2005), Sequential extraction of heavy metals during composting of sewage sludge, Chemosphere, 59, 801-810.

Banegas V., Moreno J.L., Moreno J.I., Garcia C., Leon G. and Hernandez T. (2007), Composting anaerobic and aerobic sewage sludges using two proportions of sawdust, Waste Management, 27, 1317-1327. 
Bernal M.P., Sanchez-Monedero M.A., Paredes C. and Roig A. (1998), Carbon mineralization from organic wastes at different composting stages during their incubation with soil, Agriculture, Ecosystems and Environment, 69, 175-189.

Bernal M.P., Alburquerque J.A. and Moral R. (2009), Composting of animal manures and chemical criteria for compost maturity assessment: A review, Bioresource Technology, 100, 5444-5453.

Cofie O., Kone D., Rothenberger S., Moser D. and Zubruegg C. (2009), Co-composting of faecal sludge and organic solid waste for agriculture: Process dynamics, Water Research, 43, 4665-4675.

de Guardia A., Petiot C., Rogeau D. and Druilhe C. (2008), Influence of aeration rate on nitrogen dynamics during composting, Waste Management, 28, 575-587.

de Guardia A., Mallard P., Teglia C., Marin A., Le Pape C., Launay M., Benoist J.C. and Petiot C. (2010), Comparison of five organic wastes regarding their behavior during composting: Part 1, biodegradability, stabilization kinetics and temperature rise, Waste Management, 30, 402-414.

Garcıa C., Hernandez T. and Costa F. (1993), Evaluation of the organic matter composition of raw and composted municipal wastes, Soil Science and Plant Nutrition, 39, 99-108.

Gazi A.V., Kyriacou A., Kotsou M. and Lasaridi K.E. (2007), Microbial community dynamics and stability assessment during green waste composting, Global NEST Journal, 9(1), 35-41.

Jimenez I.E. and Garcia P.V. (1991), Relationships between organic carbon and total organic matter in municipal solid wastes and city refuse compost, Bioresource Technology, 41, 265-272.

Komilis D.P., Karatzas E. and Halvadakis C.P. (2005), The effect of olive mill waste on seed germination after various pre-treatment techniques, Journal of Environmental Management, 74, 339-348.

Lu Y., Wu X. and Guo J. (2009), Characteristics of municipal solid waste and sewage sludge cocomposting, Waste Management, 29, 1152-1157.

Meunchang S., Panichsakpatana S. and Weaver R.W. (2005), Co-composting of filter cake and bagasse; by-products from a sugar mill, Bioresource Technology, 96, 437-442.

Moldes A., Cendon Y. and Barral M.T. (2007), Evaluation of municipal solid waste compost as a plant growing media component, by applying mixture design, Bioresource Technology, 98, 3069-3075.

Sanchez-Monedero M.A., Roig A., Paredes C. and Bernal M.P. (2001), Nitrogen transformation during organic waste composting by the Rutgers system and its effects on $\mathrm{pH}, \mathrm{EC}$ and maturity of the composting mixtures, Bioresource Technology, 78, 301-308.

Stentiford E.I. (1996), Composting control: principles and practice. In: De Bertoldi M, Sequi P, Lemmes B, Papai T. (Eds.), The Sciences of Composting. Blakie Academic and Professional, Glasgow.

Tam N.F.Y. and Tiquia S. (1994), Assessment toxicity of spent pig litter using a seed germination technique, Resources, Conservation and Recycling, 11, 261-274.

Tremier A., de Guardia A., Massiani C., Paul E. and Martel J.L. (2005), A respirometric method for characterizing the organic composition and biodegradation kinetics and the temperature influence on the biodegradation kinetics, for a mixture of sludge and bulking agent to be co-composted, Bioresource Technology, 96, 169-180.

Wei Z.M., Xi B.D., Zhao Y., Wang S.P., Liu H.L. and Jiang Y.H. (2007), Effect of inoculating microbes in municipal solid waste composting on characteristics of humic acid, Chemosphere, 68, 368-374.

Wong J.W.C, Mak K.F., Chan N.W., Lam A., Fang M., Zhou L.X., Wu Q.T. and Liao X.D. (2001), Cocomposting of soybean residues and leaves in Hong Kong, Bioresource Technology, 76, 99-106.

Zucconi F., Forte M., Monac A. and de Bertoldi M. (1981), Biological evaluation of compost maturity, Biocycle, 22, 27-29. 